\title{
Desejo, imaginação e criação: crítica social e crítica histórica em André Breton
}

\author{
Desire, imagination, and creation: \\ social and historical criticism in André Breton \\ João Emiliano Fortaleza de Aquino \\ http://orcid.org/0000-0003-0285-8628 - E-mail: emiliano.aquino@uece.br
}

\begin{abstract}
RESUMO
Provocado pelas críticas de Anselm Jappe e Eduardo Subiratis ao surrealismo, nas quais esses autores sugerem uma identificação desse movimento de vanguarda ao processo de modernização burguesa, o artigo se propõe a mostrar que a crítica social do presente e a crítica histórica do passado são inseparáveis em André Breton e seus camaradas surrealistas. Para isso, apresenta e explica os conceitos que se tecem na concepção surrealista, tais como desejo, imaginação e criação histórica.
\end{abstract}

Palavras-chave: Surrealismo. André Breton. Desejo. Imaginação. Criação histórica.

\begin{abstract}
Provoked by Anselm Jappe and Eduardo Subiratis' criticism of Surrealism, in which these authors suggest an identification of this vanguard movement with the process of bourgeois modernization, the article proposes to show that the social critique of the present and the historical critique of the past are inseparable in André Breton and his Surrealist comrades. To this end, it presents and explains the concepts that are woven into the Surrealist conception, such as desire, imagination, and historical creation.
\end{abstract}

Keywords: Surrealism. André Breton. Desire. Imagination. Historical creation. 
A Mirtes Amorim, que nos ensinou sobre a imaginação e a criação histórica.

Le présent est le seul temps qui est véritablement à nous, et dont nous devons user selon Dieu. Pascal, Lettres à Mlle. de Roannez, VIII

Este artigo busca pensar o problema apresentado por alguns autores que ligam a subjetividade construída pelas vanguardas - neste caso, especificamente o surrealismo - à "subjetividade estruturada pelo valor" (JAPPE, 1999, p. 196) ou que vêem, em sua "dialética civilizatória", atravessar um "princípio de dominação civilizatória" (SUBIRATIS, 2001, p. 32). ${ }^{1}$ Nesses julgamentos, nos quais se apresenta uma concepção extremamente unilateral da ultrapassagem histórica dos modos de vida pré-modernos, toma-se a feição modernista da experiência surrealista numa identificação - involuntária para um, voluntária para outro - com o processo de modernização burguesa.

A interpretação em favor da qual este artigo procura argumentar é a de que, ao assumir positivamente o elemento destrutivo da modernidade em face das tradições pré-modernas, André Breton (1896-1966) e os surrealistas assentam nele as possibilidades de criação histórica. Assim, perder-se-ia naquelas análises críticas a compreensão de que no surrealismo se encontram experiências e formulações de uma outra modernidade, cujo ponto em comum com a sociedade moderna efetiva é o elemento destrutivo que ela porta com relação tanto à tradição quanto à própria modernidade burguesa e do que nela há também de "passado".

Apoiado numa positiva representação desse destrutivo da modernidade burguesa e já situado nessa mesma experiência social, Breton e, com ele, os surrealistas posicionam-se contra a forma social da modernidade estabelecida e, nessa contraposição, constituem perspectivas próprias do moderno. Essas perspectivas não se apresentam como solidárias à modernização, no sentido burguês, das relações sociais (a universalização da forma-valor e dos modos de comportamento e formas de consciência que lhe correspondem). Bem distintamente, eles compreendem o moderno - e isso constitui sua específica postura modernista - como liberação dos constrangimentos dados nos modos de vida pré-modernos, constrangimentos que, sob outras condições e em novas formas históricas, se reapresentam na modernidade burguesa.

Desse modo, o modernismo dos surrealistas contém, nessa posição crítica do presente, e como necessária contraface daquilo que é positivamente assumido nesse moderno, um essencial antimodernismo, expresso principalmente na recusa da forma de racionalidade que, imanente às atuais relações sociais, organiza a experiência social moderna. São recusas de uma forma de racionalidade abstrata e exterior, contraposta às experiências dos indivíduos, mas que as organiza e as constrange, e que se materializa numa organização reificada da vida cotidiana. A contraposição do desejo e da imaginação a essa forma de racionalidade expressa uma continuidade da crítica do domínio da abstração que é essencial à racionalidade da sociedade mo-

\footnotetext{
${ }^{1}$ Subiratis toma como solidária de suas posições a crítica do surrealismo pelos situacionistas, investindo-a unilateralmente de um caráter que ela não tem, a saber, a identificação imediata entre a destruição da tradição, dos costumes e da linguagem cotidiana, a crítica do conceito de realidade etc., pelo surrealismo, e a nossa atual experiência de estetização dos meios de comunicação de massa e do consumo mercantil.
} 
derna: o "reino da lógica", o "racionalismo absoluto", segundo os termos de Breton no Manifesto do surrealismo (1924). ${ }^{2}$

\section{Tzara, Breton e a emergência da singularidade subjetiva}

O elemento fundamental da representação bretoniana da experiência moderna se refere não apenas ao que nela há de exaustão, de esgotamento da transmissão cultural, mas também ao que nela se explicita da impossibilidade de, em qualquer outra situação, ocorrer com verdade semelhante transmissão. Breton apresenta uma assunção do moderno como experiência de ruptura com a tradição, posição que é inseparável da crítica de toda e qualquer transmissão, tradição, continuidade e mesmo da própria experiência histórica como instância de validação de valores, comportamentos, linguagens.

É essa mesma posição crítica quanto à transmissão cultural que se manifesta com relação ao presente. A ruptura com a tradição é concebida positivamente porque a renúncia à herança cultural permite o aparecer, o manifestar-se de uma singularidade subjetiva que é também o fundamento do distanciamento e da crítica da presente sociedade. É essa singularidade subjetiva que, ao recusar uma determinada tradição e questionar a validade de qualquer outro processo de transmissão cultural, se afirma como base da crítica da própria experiência social moderna. Assim, a afirmação do moderno, por parte de Breton e dos surrealistas, se se coloca também em nome da ruptura com a tradição e os valores do passado, coloca-se primeiramente em nome de uma singularidade subjetiva que, negada pela tradição e, em geral, pelos termos de qualquer transmissão cultural, se sente negada nas - e se põe a negar as - formas dominantes do mundo moderno.

A ruptura não apenas com a valorização de uma determinada tradição, mas com a própria experiência da transmissão cultural que toda tradição implica, se afirma já nos futuristas italianos: "Compreendemos... nossa bela e mendaz inteligência nos afirma que somos o resumo e o prolongamento de nossos ancestrais. - Talvez!... Que seja!... Mas o que importa? Não queremos entender! Ai de quem nos repetir estas infames palavras!..." (MARINETTI, 1980, p. 36). Em 1918, num manifesto que teria influência fundamental sobre Breton (1969), Tristan Tzara faz eco a essa divisa, ao propor a "abolição da memória". Mas, diferentemente de Marinetti, Tzara manifesta um distanciamento da recorrente categoria da "novidade". Afastando-se criticamente deste conceito, Tzara (1982, p. 137 ss) afirma que esse tipo de novidade apenas reinsere o seu oposto: o velho; ela "se assemelha à vida como a última aparição de uma prostituta prova o essencial de Deus". O desejo da "novidade", prova de um "não-me-importismo ingênuo", segundo Tzara, já estaria ele mesmo "envelhecido".

Ao invés de recorrer, em sua reflexão, às modernas condições de existência, caracterizadas pelas ciências e pelas máquinas, como o faz Marinetti, que encontra nelas as novas condições da arte e da literatura, Tzara se remete fundamentalmente à singularidade subjetiva, que fala sempre de si e, reivindicando a solidão, coloca-se em posição de afastamento e desconfiança das relações genéricas, sociais - enfim, da "comunidade". Por isso, essa mesma singularidade subjetiva se opõe esteticamente a qualquer possibilidade de objetividade e validade universal da obra de arte. $^{3}$ Filosoficamente, contrapõe-se a qualquer pretensão de sistema, de

\footnotetext{
2 Para uma explicação um pouco mais ampla e concreta da crítica social de Breton, cf. Aquino (2019).

3 "Uma obra de arte jamais é bela, por decreto, objetivamente, para todos. A crítica é, portanto, inútil, não existe senão subjetivamente, para cada um, e sem o menor caráter de generalidade". E: "A arte é coisa privada, o artista a faz para si". (TZARA, 1982, p. 139; 143).
} 
ordem ou princípio unificador na ordem do saber. ${ }^{4}$ Num gesto de ruptura radical com a tradição, incluídas as próprias arte e estética modernas, Tzara manifesta com igual intensidade uma negação de quaisquer universalidades e objetividades conceitual ou estética que poderiam caracterizar as noções modernas ou antigas de conhecimento, de representação artística etc. Seus juízos acerca do caráter singular, subjetivo da criação e da fruição expressam um ponto de vista que não apenas se distancia da tradição, mas insiste também na incomunicabilidade absoluta no plano do gosto e do conhecimento.

Nessa posição, há tanto uma crítica explícita das exteriorizações sociais que, sob a "lógica", a "ordem", o "sistema" negam a subjetividade, a singularidade, quanto uma denúncia da falsidade da universalidade e da comunicabilidade sob a forma-arte. Longe de uma negação ingênua e irrefletida, como aparece à primeira vista, o que é particularmente reforçado pelo seu estilo, os manifestos dadaístas de Tzara propõem uma reflexão sobre o antagonismo existente entre a intenção intrínseca às obras de arte tradicionais à comunicabilidade e à universalidade, por um lado, e, por outro, a experiência social que nega toda comunicação e universalidade. ${ }^{5}$

Os primeiros manifestos dadaístas datam de 1916, contemporâneos das primeiras experiências de escrita - que estão na fundação do modernismo ocidental - que renovam a linguagem poética, precisamente na forma da expressão do não-comunicável. A afirmação positiva, por esses manifestos, da incomunicabilidade da interioridade subjetiva, que aparece em sua recusa de qualquer instância universal, constitui fundamentalmente uma posição crítica da banalização da linguagem - artística, científica, cotidiana - nos marcos das relações mercantis, denúncia que não é feita através de qualquer ideia de "perda" ou "decadência"; e oferecem, assim, um sentido crítico às novas experiências da escrita, ainda que mantenham uma diferença com relação a elas, ao colocarem em questão a própria noção de obra. O que ganha importância neste gesto é a tematização, que se tornará permanente nas experiências de vanguarda na Europa, do problema da própria linguagem.

Ao fazer a denúncia da falsa comunicação artística, em sua forma tradicional, e a afirmação positiva da singularidade não-comunicativa, Tzara assume uma radical recusa se solidarizar com qualquer ideia do moderno, evitando, assim, alguma forma de afirmação das objetivações sociais que, modernamente, tanto quanto tradicionalmente, implicam uma negação da singularidade.

As posições de Breton são diretamente - seja lhes dando continuidade, seja confrontando-Ihes - matizadas por essas posições de Tzara acerca da centralidade da singularidade subjetiva. Diferentemente deste, que se nega a uma qualquer representação do "moderno", em nome da afirmação da singularidade e da subjetividade, Breton se propõe a pensar a poesia nos termos de suas condições modernas, como o faz Marinetti, embora apresentando um traço distinto quanto à concepção da ruptura que a modernidade opera.

Mas é este traço que dificilmente pode se distanciar da afirmação radical da singularidade feita por Tzara. Frente aos manifestos de Marinetti, Breton coloca em questão não apenas uma determinada tradição, mas também a legitimidade de toda e qualquer tradição, toda e qualquer transmissão cultural, em nome do processo de singularização que, aos seus olhos e aos de Tzara, a superação da tradição promete. Enquanto Marinetti (1980b, p. 81) sustenta com o objetivo de superação de "toda psicologia" - a destruição do "eu", Tzara e Breton, ao fa-

\footnotetext{
4 "A ciência me repugna desde que ela se torne sistema-especulativo, perde seu critério de utilidade - de qualquer forma inútil -, pelo menos individual. Eu odeio a objetividade gordurosa e a harmonia, esta ciência que encontra tudo em ordem. [...] Eu sou contra os sistemas, o mais aceitável dos sistemas é aquele que tem por princípio não ter princípio nenhum". (TZARA, 1982, p. 142-143).

${ }^{5}$ Por "obras de arte tradicionais", entenda-se aqui particularmente a arte realista do século XIX e a "literatura psicológica" da passagem do século XIX ao século XX.
} 
zerem a crítica da literatura psicológica e da concepção unitária do sujeito, insistem no processo de singularização que resultaria da crise da tradição e na contraposição entre a singularidade subjetiva e o mundo social, ao mesmo tempo em que se distanciam da representação positiva, pelo futurismo, da massa, da multidão.

\section{Breton e a ideia do moderno}

Em Breton, o reconhecimento da experiência moderna como aquela em que, dada a emergência da referida singularidade solitária, a herança cultural se torna tanto incômoda quanto impossível, significa que é a própria tradição, a própria transmissão cultural que agora, a partir da própria experiência moderna, se torna passível de crítica. A partir da experiência moderna de recusa, em nome de um pretendido processo de singularização, de toda forma de recebimento da produção cultural e da efetividade histórica do passado, torna-se possível, para Breton, o rompimento com a representação de que semelhante recebimento, sob a forma de transmissão e herança cultural, possa ser legítima. É neste sentido que sua assunção do "moderno" é inseparável da renúncia à experiência histórica.

A esperada afirmação da singularidade, com base na ruptura com a tradição, se apresenta como uma ratio cognoscendi dos limites da experiência e do conhecimento históricos e, deste modo, a própria experiência histórica, ao ser recusada, é concebida como essencialmente limitada do ponto de vista do aprendizado que ela pode oferecer para o presente. Trata-se da formulação de uma "ideia moderna da vida" que remete diretamente à crítica da própria história como lugar de experiência. A afirmação da singularidade subjetiva - que é o seu ponto de partida para a crítica da tradição e que é concebida como resultado da "destruição" desses processos históricos de transmissão cultural - conduz certamente a uma afirmação do "moderno", mas como "ideia" do moderno e não como experiência social efetiva. Se a experiência moderna efetiva é recusada, o processo destrutivo que ela supõe - destruição da antiga linguagem, dos antigos modos de expressão - não deixa de ser positivamente apanhado, mantido nesta ideia do moderno.

O que a experiência moderna possibilita compreender é antes uma verdade que, mesmo negativamente experimentada, é assumida como ponto de partida potencialmente emancipatório. Isto se dá na afirmação da singularidade em face dos constrangimentos exteriores dados tanto pela tradição, quanto pela experiência social presente. Quando retoma, nas Entretiens, a sua representação do moderno nos anos iniciais da experiência surrealista, ele o define ressaltando o elemento emancipatório, em vista dos constrangimentos, que tal representação então lhe evocava: o moderno seria "a liberação total dos modos de pensamento e de expressão pré-estabelecidos, em vista da promoção necessária dos modos de sentir e de dizer que sejam especificamente novos e cuja busca implica, por definição, o máximo de aventura" (BRETON, 1969, p. 42).

Referindo-se especificamente ao primeiro pós-guerra europeu, Breton (1988a, p. 197) reconhece na experiência moderna um duplo aspecto: "a inutilidade de escrever a história", pois "toda reconstituição é impossível", e a conclusão de que "nenhuma verdade merece permanecer exemplar". Ainda que referida à experiência negativa da guerra, marco de toda uma nova reflexão sobre a especificidade do moderno, essas afirmações de Breton indicam a pretensão de um alcance mais amplo. Para ele, a referência à guerra não deve, quanto à crítica do valor da experiência histórica, nem mesmo ser tomada como central, pois não está dada a possibilidade de se recolherem os "ensinamentos" ("enseignements", que ele mesmo grafa com aspas) da 
guerra, devendo essa tarefa ser abandonada. Por isso mesmo, não poderia ser ela a oferecer esse "ensinamento" sobre a experiência histórica e cultural. Em 1934, Benjamin (1993, p. 114115) notará que "os combatentes tinham voltado silenciosos do campo de Batalha. Mais pobres em experiências comunicáveis, e não mais ricos". É essa impossibilidade essencial de construção de experiência comum, de uma continuidade qualquer de experiência com base na guerra expressando também o caráter emblemático da primeira guerra quanto à ruptura com a experiência passada - que Breton expressa. A experiência negativa da guerra, da qual decorre a impossibilidade de que ela ofereça ensinamentos, é muito mais uma ocasião em que ganha luz essa impossibilidade de - e, melhor, esta renúncia consciente a - um aprendizado histórico, não primeiramente nos termos de um conhecimento historiográfico, mas antes de tudo no que diz respeito aos "ensinamentos" e seu valor para a experiência presente.

Não há dúvida de que, quanto às motivações de ordem subjetiva, coube - no entender de Breton - um papel fundamental à experiência da guerra numa assunção consciente da ruptura com a história e a transmissão culturais. "Para não experimentar do desprazer, fomos conduzidos", diz Breton (1988a, p. 216), num texto escrito no ano do armistício, "a dar pouca importância a todas as coisas. E pedimos a nossos poetas, a nossos filósofos o mesmo sacrifício". Essa conduta, nomeada por ele de "assalto ao razoável" (l'assaut du raisonnable), expressa uma busca consciente, naquele momento histórico, por assumir a destruição da tradição, a desvalorização da experiência histórica e cultural, através de uma relativização de tudo o que antes fora estabelecido. Mais do que um juízo sobre as consequências da primeira guerra, essa posição expressa a renúncia à experiência histórica, cultural, literária do passado como lugar de verdade, como fundamento para a experiência atual ou mesmo, em seu aspecto mais amplo, como instância explicativa da experiência humana. "Não nos é deixada a possibilidade de nenhuma certeza, [...] todas as interpretações são válidas, diz em 1921 Breton (1988b, p. 416). Precisamente por isso, a ideia do "moderno" representa uma emancipação do peso da história, enquanto tradição, ensinamento e, no limite, enquanto instância doadora de sentido, de explicitação da verdade do humano, de validação de normas comportamentais e de modos de expressão.

A afirmação da inutilidade do conhecimento histórico manifesta uma negação da própria experiência histórica, tendo em vista a suspensão do moderno por ele ideado de um qualquer curso contínuo dos fatos. Pode-se pensar essa postura como a do 'esquecimento ativo', sugerido por Nietzsche. Já na crítica futurista da "sabedoria" se expressam uma renúncia a encarar o tempo presente com base no que foi produzido no passado e uma insistência em tomar o específico e o diferente da experiência presente com relação a outras experiências históricas, renúncia e insistência que também podem ser pensadas nos termos nietzschianos da "oposição entre a sabedoria e a vida". Antecipando-se a Marinetti, o filósofo alemão também pensa que devamos "nos alegrar uma vez de todo coração com a nossa ignorância", reconhecendo "com prazer aos homens supra-históricos que eles possuem mais sabedoria do que nós, desde que estejamos certos de possuir mais vida do que eles: pois só assim nossa ignorância terá de qualquer modo mais futuro do que a sua sabedoria" (NIETZSCHE, 2003, p. 16). Com Nietzsche, Breton afirma o "esquecimento" e a "inutilidade" do conhecimento histórico como condições para um posicionamento diante do presente. Nas palavras do fundador do surrealismo, é o caso de "se colocar logo de saída fora do conhecido e do esperado" (1988c, p. 434).

Precisamente por isso, a representação bretoniana do moderno implica também um distanciamento do presente. A sua posição subjetiva de auto-exílio do tempo presente, que é uma posição de extemporaneidade do moderno, não deixa de ser uma parte integrante da própria ideia do moderno tal como o representa Breton (e, portanto, do esquecimento que ele requer). Ao buscar na experiência moderna este além que escapa à sua efetividade constituída, bus- 
cando pensá-la como contendo possibilidades que vão além do simplesmente dado (ou herdado), ele afirma uma negação do "tempo", como negação de determinados modos de exigências do presente. "Eu não me coloco unicamente no tempo", diz Breton (1988a, p. 238), fazendo eco - numa recusa à "ação" - à divisa de Tzara (1982, p. 143) segundo a qual "frente à eternidade toda ação é vã". ${ }^{6}$ Breton recusa o tempo antes de tudo como uma recusa a se limitar à sua própria época, a ter com ela uma relação apenas positivadora e, em última análise, uma relação de identificação. O reconhecimento e mesmo a reivindicação da perda de qualquer referência ou sentido herdado, pelo qual os indivíduos possam se nortear, se articulam, como em Nietzsche, com a necessidade do desvio com relação ao próprio presente, com base numa recusa do tempo que, embora dirigida principalmente ao presente, também diz respeito ao passado.

Numa convergência com a afirmação da singularidade subjetiva por Tzara, esta extemporaneidade tem como fundamento precisamente o "espírito", o subjetivo. Ao extrair a ideia do moderno de um curso qualquer da experiência histórica, Breton busca fazê-la conter aquela reserva subjetiva que escapa ao efetivo, seja na efetividade da tradição, seja na efetividade de seu próprio tempo. Essas possibilidades subjetivas podem permanecer obstaculizadas caso o moderno, por ele ideado, seja tomado como positivação de uma experiência histórica reconhecida como "útil" e veramente "reconstituída".

Se a ideia do moderno significa, em sua ruptura com os valores tomados como absolutos no passado, uma experiência de liberação da história e da tradição, é a assunção dessa mesma liberação - enquanto possibilidade de um processo de singularização - que exige a suspensão da história, da utilidade de seu conhecimento e até mesmo de sua reconstituição como forma de saber. Para Breton, conforme nos diz Gérard Legrand (1997, p. 53), "a história é inseparável da maneira que é contada". Sua renúncia aos valores herdados do passado tem uma relação com a suspeita tanto da história, como experiência, quanto do conhecimento histórico, como forma de saber, como narrativa.

\section{Desejo e imaginação histórica}

A reivindicação da singularidade subjetiva por Breton é inseparável da ruptura da concepção unitária do sujeito e tem, justamente na crítica da representação do sujeito centrado na consciência, um componente fundamental do distanciamento tanto da experiência histórica do passado quanto da do presente. Uma anotação num carnet do ano de 1924, contemporâneo já de sua leitura de Freud e da elaboração do primeiro manifesto surrealista, indica uma desconfiança de qualquer representação do passado e do presente: "A vida anterior?", pergunta-se ele, lembrando aí o título de um importante poema de Les fleurs du mal. "O que me dá conta do passado e mesmo da vida é apenas a memória. [...] E se a memória for apenas um produto da imaginação?" (BRETON, 1988d, p. 455-456). Esta reflexão negativa quanto à suposta efetividade dos conteúdos mnêmicos, desconfiança que pode ser pensada com base no conceito freudiano de lembrança encobridora, tanto concebe positivamente o poder transfigurador da imaginação quanto põe em dúvida a "vida", a representação comum da "vida" (que retorna, no Manifeste du surréalisme de 1924, como vie réelle, "vida real") e a capacidade de uma reconstituição verdadeira do passado, pois submete a memória à suspeita de enquadramento nos me-

\footnotetext{
${ }^{6}$ Sobre o significado dessa recusa da ação, por Breton, enquanto uma recusa dos "imperativos práticos", remeto mais uma vez a Aquino (2019).
} 
canismos psíquicos que tendem a produzir falsas representações do passado segundo as necessidades presentes de recalcamento e/ou repressão.

Sob o conceito de "lembranças encobridoras", Freud se refere à produção - pela ação inconsciente da censura - de lembranças que, através da condensação e do deslocamento, visam encobrir aquelas experiências desagradáveis, substituindo-as, na memória consciente, por outras ou de menor importância (lembranças indiferentes) ou extremamente modificadas ou mesmo invertidas. Essas lembranças substitutas se constituem e se preservam pelo seu vínculo associativo com outro conteúdo que está recalcado. ${ }^{7}$ Na linguagem que usa neste período, Breton situa a memória precisamente na instância consciente. No Manifeste de 1924, ele a opõe ao sono e ao sonho, afirmando que "o homem quando para de dormir é, antes de tudo, o joguete de sua memória" (BRETON, 1988e, p. 317). A desconfiança do passado e do presente se estabelece, dessa maneira, em íntima ligação com a afirmação de uma instância outra da subjetividade, afirmação que em um só movimento põe em suspeita tanto a realidade exterior (o passado, a vida presente), quanto a memória, a instância consciente. Trata-se justamente do seu esforço por assumir um ponto de vista outro que não o da realidade à qual se ligaria a consciência, esforço que dá forma ao seu distanciamento da tradição e do presente, ao seu esquecimento e à sua extemporaneidade.

Numa recepção da psicanálise cujo rigor não deve ser procurado, mas que deve ser ainda mais bem refletida, Breton tende a ver, na "experimentação do inconsciente" (l'épreuve de l'inconscient), a experimentação de uma instância mais autêntica e verdadeira da alma humana, em contraposição à "exterioridade". Apresenta-se aqui precisamente o que ele também chama de profondeurs de notre esprit, "profundezas de nosso espírito". É a partir desse lugar (o esprit), e justamente em nome de sua afirmação, que se desenvolve em Breton a crítica da tradição e o afastamento do presente. Este lugar remete a um recuo em direção a uma espécie de lugar do autêntico, movimento que implicará sempre, em seus textos, uma oposição entre uma interioridade e uma exterioridade, mesmo quando ele procura ultrapassar essa oposição através do conceito de surréalité.

Embora, do ponto de vista da própria experiência histórica e pessoal de Breton, a reflexão sobre a crise da tradição seja o ponto de partida real, do qual resulta a representação positiva do processo de singularização subjetiva (centro de sua ideia de "moderno"), é este mesmo processo de afirmação da singularidade que toma, no seu pensamento, um lugar central. Em outras palavras, o que resulta de sua reflexão da crise histórico-social da tradição se coloca na forma de uma interioridade que reivindica uma existência substancial. Certamente, não uma substancialidade no sentido filosófico-antropológico tradicional, pois, em sua recepção da teoria psicanalítica do sujeito cindido, a unicidade, a substancialidade metafísica da alma já não se mantém; mas sim, uma substancialidade ética em face da dessubstancialização ético-significativa da "realidade exterior" em razão tanto da crise da tradição quanto da sua posição de recusa da própria experiência reificada da modernidade.

Quando de seu debate com Georges Bataille, no Second manifeste du surréalisme, Breton busca justamente se afastar de uma positivação do dado, do estabelecido historicamente. Ele opõe à "genealogia" materialista battailleana - fortemente marcada por uma bem particular

\footnotetext{
${ }^{7}$ Entre as primeiras obras de Freud publicadas na França, no início dos anos 20, e que constam da biblioteca preservada de Breton, há duas em especial que retomam amplamente a discussão sobre o problema do esquecimento e da memória: Zur Psychopatologie des Alltagsleben [1901], publicada sob o título Psychopatologie de la vie quotidienne [1922], e as Vorlesungen zur Einführung in die Psychoanalyse [1916;1917], sob o título Introduction à la psychanalyse [1922]. Nestas duas obras, Freud expõe o mecanismo de esquecimento como sendo fundamentalmente provocado pela recusa de lembranças desagradáveis; é com base nesse mecanismo que ele explica as lembranças encobridoras. Cf. Freud (1987).
} 
leitura de Nietzsche - uma ideia de possibilidade. Com base na oposição entre interioridade e exterioridade, Breton afirma uma limitação ético-significativa da história efetiva, pois ela reduzir-se-ia ao "que é" e não alcançaria o "que pode ser". Trata-se, para ele, de

cessar este mal do espírito que reside no fato de pensar muito dolorosamente que algumas coisas "são", enquanto outras, que bem poderiam ser, "não são". Já dissemos que elas devem se confundir ou simplesmente se interceptar, ao limite. Trata-se, não de permanecer aí, mais de não poder fazer menos do que tender desesperadamente a esse limite. (BRETON, 1988f, p. 828).

Daí, a frase que inicia o último parágrafo do manifesto: “O homem, que erradamente se intimidaria com alguns monstruosos fracassos históricos, é ainda livre para crer em sua liberdade" (BRETON, 1988f, p. 828).

A reserva subjetiva frente à exterioridade - que, na memória, tanto quanto na consciência, oferece um registro de censura e recalque dos desejos - se apresenta essencialmente, para Breton, como uma reserva de possibilidades outras daquelas efetivadas, lembradas ou conscientemente requeridas; reserva de possibilidades situada na interioridade subjetiva, singular e da qual a efetividade histórica (e, de mesmo modo, a narrativa histórica) não pode dar conta.

Na reflexão de Breton sobre o "moderno" e em sua negação da experiência histórica, o que fundamentalmente se afirma é essa reserva de possibilidades, situada nas "profundezas do espírito" e que se opõe à exterioridade efetiva passada, tanto quanto à efetividade presente. Desse modo, duas afirmações suas ainda podem ser mobilizadas como testemunhas de seu afastamento de qualquer identificação com a forma burguesa de superação das sociedades pré-capitalistas, pois elas questionam profundamente uma qualquer concepção de história que poderia estar na sua base, legitimando-a. Relacionadas ao inacabamento prático da experiência histórica e à inexatidão cognitiva de sua narrativa, estas passagens são complementares. "É pueril dizer que uma retificação, ainda que radical, das condições de vida colocaria fim a todos os conflitos: eles se reproduziriam em outros planos, em razão da potência do desejo no homem e de sua insatisfação fundamental", diz Breton (1969, p. 272) numa entrevista a Claudine Chonez. "[A] 'História', tal como é escrita”, ele acrescenta em outra ocasião a Francis Dumont,

é um tecido de perigosas infantilidades, tendendo a nos fazer tomar por realidade acontecimentos que daquela são apenas a projeção exterior, falaciosa. [...] Querer deduzir o que quer que seja de uma tal História é quase tão vão quanto pretender interpretar o sonho levando em conta apenas seu conteúdo manifesto. (BRETON, 1969, p. 276).

Nessas passagens, a inesgotabilidade do subjetivo na instância consciente constitui simetricamente, em sua extensão, também a inesgotabilidade da experiência passada ou presente em sua efetividade imediata. A positiva afirmação dessa inesgotabilidade - centrada nas noções de desejo, imaginação, possibilidade, liberdade - aponta precisamente em direção a um lugar de autenticidade não-efetiva e jamais inteiramente efetivável do "espírito", e cuja natureza subjetiva aparece, nos textos de Breton, quando se apresenta sob a forma da oposição entre interioridade e exterioridade, oposição pela qual ele se distancia criticamente do presente e do processo histórico que o constituiu. Enfim, a reivindicação dessa interioridade, dessa "profundeza do espírito", formas nas quais se apresenta a afirmação do que tem sido chamado aqui de singularidade subjetiva, é radicalmente inseparável do seu distanciamento com relação às formas "exteriores" da "realidade" e remete, essencialmente, à sua ideia do moderno, sua ruptura com a tradição e sua posição crítica diante do presente.

Que não haja mais, do ponto de vista da herança cultural, nenhuma "verdade exemplar", que "nenhuma certeza nos tenha sido legada", isto significa, para Breton, um querer e mesmo 
requerer da exerdação da tradição como próprios da elaboração positiva de uma ideia do moderno, em cujo centro está a afirmação da singularidade subjetiva pensada sob a categoria do espírito: “Entre tantas desgraças que herdamos, é preciso reconhecer que a maior liberdade de espírito nos é deixada" (BRETON, 1988e, p. 312). É nesse movimento de afirmação ético-significativa da interioridade subjetiva e singular que Breton "desrealiza" a experiência histórica e a "vida" presente, pois uma e outra são tomadas como puras "exterioridades". Elas são negadas porque, na sua efetividade, obscurecem o desejado, não-efetivado e, finalmente, "recalcado" (refoulé). Essa "desrealização" (como a nomeia Alquié (1955)) termina precisamente por remeter a uma noção de interioridade subjetiva que se posiciona, não apenas numa extemporaneidade, mas precisamente numa "supra-realidade" (surrealité), num além da realidade imediata que, não podendo apontar para um qualquer topos do passado ou do presente, só pode assumir como fundamento o espírito.

Após essa longa exposição, é possível voltar a referir-se a Subiratis e Jappe. As análises desses autores parecem reagir, pela esquerda (mas sendo-Ihe no diagnóstico essencialmente solidárias), à concepção apresentada por P. Bürger (1987) sobre as vanguardas do início do século XX, segundo a qual a derrota histórica daquelas experiências é tomada como um fracasso e, por causa deste, numa perversa dialética, tornam-se uma construção positiva das categorias da arte na sociedade burguesa. Por se basearem numa compreensão bastante unilateral da própria modernidade burguesa, as análises de Jappe e Subiratis correm o risco de se deixar atravessar por um certo passadismo, por se apoiar numa outra e anterior forma histórica da divisão social do trabalho, como base da crítica da atual sociedade produtora de mercadorias. ${ }^{8}$

Para Breton e os surrealistas, o distanciamento da "realidade exterior" do passado e do presente, sendo inseparável da assunção do moderno, significa uma positivação estrita do destrutivo da modernidade, na qual é central aí precisamente a possibilidade da criação histórica e, portanto, a ruptura, a descontinuidade. Para eles, a destruição é inseparável da construção (ou criação). Sob o conceito de surréalité, que expressa um ideal ético de superação das antinomias, destruição e construção se conciliam. Um dos motivos do distanciamento dos surrealistas em relação aos dadaístas é precisamente a análise dos primeiros de que estes últimos se posicionariam apenas negativamente, destrutivamente. Em outras palavras, o ponto de partida dos surrealistas é a afirmação da potencialidade construtivo-criativa da destruição.

\section{Referências}

ALQUIÉ, F. Philosophie du surréalisme. Paris: Flammarion, 1955.

AQUINO, J. E. F. "Os fins lógicos nos escapam”: a crítica da alienação em André Breton. Revista Limiar, v. 6, n. 12, p. 70-87, 2019. Disponível em: https://periodicos.unifesp.br/index.php/limiar/ article/view/10016. Acesso em: 31.ago.2021.

BENJAMIN, W. Experiência e pobreza [1934]. Obras escolhidas I. 6a ed. Trad. Sérgio Paulo Rouanet. São Paulo: Ed. Brasiliense, 1993.

\footnotetext{
${ }^{8}$ Essa é a crítica é desenvolvida por Wolfgang F. Haug (1997), em termos muito duros, talvez mesmo exagerados, justamente a respeito do grupo alemão da revista Krisis, ao qual se ligou A. Jappe.
} 
BRETON, A. Alentours II. L'affaire Barrès. Oeuvres complètes I. Paris: Gallimard, 1988b.

BRETON, A. Appel du 3 janvier 1922. Oeuvres complètes I. Paris: Gallimard, 1988c.

BRETON, A. Carnet [1924]. Oeuvres complètes I. Paris: Gallimard, 1988d.

BRETON, A. Entretiens [1952]. Paris: Gallimard, 1969.

BRETON, A. Les pas perdus [1924]. Oeuvres complètes I. Paris: Gallimard, 1988a.

BRETON, A. Manifest du surréalism [1924]. Oeuvres complètes I. Paris: Gallimard, 1988e.

BRETON, A. Second manifeste du surréalisme [1930]. Oeuvres complètes I. Paris: Gallimard, $1988 \mathrm{f}$.

BÜRGER, P. Teoría de la vanguardia [1974]. Trad. Jorge García. Barcelona: Ediciones Península, 1987.

FREUD, S. Sobre a psicopatologia da vida cotidiana. Trad. Walderedo Ismael de Oliveira. Edição Standard Brasileira das Obras Psicológicas Completas de Sigmund Freud. Volume VI. Rio de Janeiro: Imago Editora, 1987.

G. LEGRAND, G. Breton: surréalisme et philosophie de l'histoire, une rencontre. In: PLOUVIER, P. et al. (Org.). Trois poètes face à la crise de l'histoire. Paris: L'Harmattan, 1997.

HAUG, W. De Nietzsche a Marx. Entrevista a Ernani Pinheiro Chaves e Isabel M. Loureiro. Praga, n. 3, p. 139-140, set./1997.

JAPPE, A. Guy Debord [1993]. Trad. Iraci Poleti. Petrópolis: Vozes, 1999.

MARINETTI, F.T. Fundação e manifesto do futurismo [1909]. Trad. A. F. Bernardini. In: BERNARDINI, F. (Org.). O futurismo italiano. São Paulo: Ed. Perspectiva, 1980a.

MARINETTI, F. T. Manifesto técnico da literatura futurista [1912]. Trad. A. F. Bernardini. In: BERNARDINI, F. (Org.). O futurismo italiano. São Paulo: Ed. Perspectiva, $1980 \mathrm{~b}$.

NIETZSCHE, F. Segunda consideração intempestiva. Da utilidade e desvantagem da história para a vida. Trad. M. A. Casanova. Rio de Janeiro: Relume Dumará, 2003.

SUBIRATIS, E. A penúltima visão do paraíso. Trad. Eduardo Brandão. São Paulo: Studio Nobel, 2001.

TZARA, T. Manifesto Dadá 1918. In: TELES, G. M. (Org.). Vanguarda europeia e modernismo brasileiro. Petrópolis: Vozes, 1982.

\section{Sobre o autor}

João Emiliano Fortaleza de Aquino

Doutor em Filosofia pela Pontifícia Universidade Católica de São Paulo, onde defendeu uma tese sobre Guy Debord (2005), com Estágio Pós-Doutoral na Universidade de São Paulo, quando realizou pesquisa sobre Walter Benjamin (2009-2010). Professor do curso de Graduação e Pós-graduação em Filosofia da Universidade Estadual do Ceará, Coordenador do Grupo de Pesquisa em Dialética e Teoria Crítica e do Grupo de Estudos benjaminianos da UECE. Tem experiência em Filosofia (nas áreas específicas de Teoria Crítica, Estética e Dialética) e em Estudos Surdos. 